\title{
CUMPRIMENTO DE SENTENÇA DO DIREITO À CONVIVÊNCIA FAMILIAR: A INSUFICIÊNCIA PROCEDIMENTAL E NORMATIVA NA TUTELA DO DOS DIREITOS INFANTOJUVENIS
}

\author{
FULFILLMENT OF THE \\ SENTENCE OF THE RIGHT TO FAMILY LIVING: \\ PROCEDURAL AND NORMATIVE INSUFFICIENCY IN \\ THE PROTECTION OF CHILDREN'S RIGHTS
}

CARLOS ALEXANDRE MORAES ${ }^{1}$

DIEGO FERNANDES VIEIRA ${ }^{2}$

\section{RESUMO}

O presente artigo tem por finalidade analisar os meios processuais voltados para o cumprimento de sentença da convivência familiar devidamente regulamentada.Assim fomentar a discussão sobre a crise processual civil que assola os processos envolvendo os conflitos existenciais e familiares. Empregou-se, para tanto, o método hipotético-dedutivoconjuntamente com o método de procedimentofuncionalista e o comparativo, e ainda, para sustentar referida pesquisa, utilizou-se do método de investigação bibliográfico e o documental. Concluindo-se que o Processo Civil voltado para a execução da convivência familiar resta prejudicado e insuficiente, inexistindo meios coercitivos adequados para o tratamento de demandas existenciais, necessitando-se urgentemente de uma nova postura jurisdicional e, ainda, de uma legislação processual própria para o tratamento e resolução dos conflitos familiares.

PALAVRAS-CHAVE: Afetividade. Código de Processo Civil. Criança e Adolescente. Direitos da Personalidade. Família.

1 Professor Permanente do Programa de Doutorado e Mestrado em Direito do Centro Universitário Cesumar (UniCesumar); Pós-Doutor em Direito pelo Centro Universitário Cesumar (UniCesumar), Doutor em Direito pela FADISP; Doutor em Ciências da Educação pela UPAP; Mestre em Direito pelo Centro Universitário Cesumar (UniCesumar); Pesquisador Bolsista Modalidade Produtividade em Pesquisa para Doutor PPD - do Instituto Cesumar de Ciência, Tecnologia e Inovação (ICETI); Advogado; ORCID iD https://orcid.org/0000-0002-2230-0368. Lattes: http://lattes.cnpq.br/7327808122990666. E-mail: camoraes.adv@hotmail.com.

2 Mestrando no programa de Pós-Graduação em Ciências Jurídicas (PPGCJ) pelo Centro Universitário de Maringá - Unicesumar - Bolsista do programa de Suporte à Pós-Graduação de Instituições Particulares (PROSUP/CAPES); Graduado em Direito pelo Centro Universitário de Cesumar - Unicesumar; Graduando em Administração pelo Centro Universitário Leonardo da Vinci - Uniasselvi. ORCID iD https://orcid.org/0000-0001-5351-9023. Lattes http://lattes.cnpq. br/8603486646565986. E-mail: diego.vieira_180@hotmail.com. 


\section{ABSTRACT}

The purpose of this article was to analyze the procedural means aimed at fulfilling the sentence of family life properly regulated, based on the scientific research already carried out in the area, the current legislation and the jurisprudence. Thus, to foster the discussion on the civil procedural crisis that plagues the processes involving existential and family conflicts. For this purpose, the hypothetical-deductive method was used with the functionalist method and the comparative method, and still, to support this research, the bibliographic and documentary research method was used. In conclusion, the Civil Procedure aimed at the execution of family life remains impaired and insufficient, with no adequate coercive means for the treatment of existential demands, urgently needing a new jurisdictional stance and, still, its own procedural legislation:for the treatment and resolution of family conflicts.

KEYWORDS: Affectivity. Civil Procedure Code. Child and teenager. Personality Rights. Family.

\section{INTRODUÇÃO}

O Estado, no momento em que legisla sobre questões existenciais envolvendo a família e o desenvolvimento humano, coloca sobre si a responsabilidade de lidar e resolver os conflitos advindos deste núcleo relacional. Nesta perspectiva sociojurídica, o atual e constitucionalizado Direito das Famílias se voltou para a proteção e felicidade de seus membros, em especial do vulnerável, a pessoa do filho. Nota-se que o ordenamento jurídico veio a conceder as crianças e adolescentes especiais direitos e particulares princípios voltados para a proteção da infância e juventude, um desses é o denominado direito à convivência familiar.

Desse modo, o direito à convivência familiar passou a ser um direito não de exclusividade dos genitores, mas também do filho. Direito este fundamental e imprescindível para o desenvolvimento e tutela dos direitos da personalidade. Não sendo mais concebido apenas como um dever moral, mas sim uma obrigação jurídica de fazer, de prestar a assistência, além da material (alimentar), mas também emocional e psicológica (convivência).

Todavia, as mudanças ocorridas no direito material parecem não ter alcançado o direito processual, visto que ainda existe uma resistência de caráter cultural em se falar de execução forçada da convivência familiar quando o genitor não guardião injustificadamente deixa de conviver com o filho. Tornando-se visível a necessidade de se discutir e repensar o processo de cumprimento de sentença envolvendo o direito à convivência familiar.

A presente pesquisa fundou-se no método hipotético dedutivo, utilizando-se de uma análise qualitativa, bem como em pesquisa bibliográfica e documental, tendo por objetivo demonstrar a insuficiência processual civil no que tange a tutela do direito à convivência familiar quando o genitor não guardião se mantém omisso em seu dever de conviver.

Organizou-se a pesquisa em três partes, na primeira foi dado enfoque no direito à convivência familiar e seus reflexos para o crescimento e desenvolvimento humano. Na segunda parte, foram abordadas as questões processuais no que tange o cumprimento forçado da convivência familiar. E na terceira e última parte, demonstrou-se possibilidades hermenêuticas para a tutela deste direito infantojuvenil, além da necessidade de uma legislação processual própria para a solução dos conflitos familiares. 
Propõe-se com o presente estudo, uma reflexão acerca da importância da convivência familiar, bem como da necessidade procedimental de efetivação deste direito quando não cumprido de forma voluntaria. O foco do artigo não é a imposição de "amor" sobre as regras legais, mas sim na promoção de uma parentalidade responsável, de um agir consciente e sobretudo, uma tutela jurisdicional efetiva, e não apenas declaratória de direitos.

\section{DO DIREITO FUNDAMENTAL DA CRIANÇA E ADOLESCENTE DE CONVIVER COM AMBOS OS GENITORES}

O direito à convivência familiar se encontra previsto na Constituição Federal de 1988 no art. 227, no Estatuto da Criança e do Adolescente no art. 3, no Código Civil no art. 1.589 e ainda na Lei n. 12.318/2010 que trata sobre Alienação Parental. Os genitores têm o dever de respeito e efetivação deste direito em face da pessoa do filho, e esta obrigação legal decorre do princípio da parentalidade responsável (art. 226, $\S 7^{\circ}$, da CF), em casos de perda da guarda física do filho, que geram o dever de tê-lo em sua companhia (art. 1.634, II, do CC), bem como na obrigação de ambos os pais de assistência integral (aspectos físicos, psíquicos, morais e espirituais) do filho (art. 229 da CF, 22 do ECA e 1.634, I, do CC).

Fala-se ainda na existência do princípio constitucional da convivência familiar aplicado ao Direito das Famílias. "Como consequência do princípio do melhor interesse tem-se o princípio da convivência familiar, compreendido no direito de pais e filhos de conviverem uns com os outros" (ANGELINI NETA, 2016, p. 84). Este princípio visa exatamente a preservação da relação parental nitidamente de cunho prestacional, que impõe não só à família, mas também ao Estado a promoção e efetivação desde direito da criança e do adolescente. (AMARILLA, 2014).

O rompimento afetivo entre os genitores não irá romper os vínculos advindos da parentalidade, esta última se mantém inalterada, o que de fato ocorre é uma adaptação do exercício da autoridade parental, que tem reflexo direto na forma da convivência entre pais e filhos. Grisard Filho (2016, p. 110) elenca que: "A ruptura, em si, não provoca modificações nas relações entre os sujeitos da guarda, mas estabelece, inevitavelmente, uma nova forma de se vincularem". Desta forma, resta-se claro que a cessão da convivência entre os pais, não irá fazer cessar a convivência deles com os filhos, mesmo residindo em casas distintas. (LÔBO, 2008).

O direito em análise se converte nas palavras de Madaleno (2007, p. 119) como sendo "um direito conferido a todas as pessoas unidas por laços de afeto, de manterem a convivência e o intercâmbio espiritual quando estas vias de interação tiverem sido rompidas pela separação física dos personagens".

O objetivo deste direito, basicamente, é salvaguardar as relações familiares, sejam elas advindas da consanguinidade ou da socioafetividades, abarcando para além das figuras parentais. A convivência familiar também abrange o direito de correspondência entre pais e filhos (STRANGER, 1991), falando-se hoje até mesmo de uma convivência virtual e comu- 
nhão com a física para assim se incentivar e fomentar a maior interação do genitor não-guardião com sua prole.

Atualmente a família é vista como um locus privilegiado, onde ocorre de fato o desenvolvimento da personalidade de todos os membros (GAMA, 2008). Sendo exatamente neste lugar de interação que a família irá ultrapassar a sua concepção eudemonista, para se tornar principalmente solidarista, vez que na família os seus membros são corresponsáveis uns pelos outros. E mesmo que a liberdade existencial seja um dos pilares do Estado Democrático de Direito, esta autonomia voltada para o Direito das Famílias, tem como objeto "opções conjugadas", que impõem certo limite nesta liberdade, na exata medida que as escolhas individuais irão refletir diretamente aos outros membros deste núcleo afetivo e relacional. (TEIXEIRA; TEPEDINO, 2020).

Assenta-se nesta corresponsabilidade o direito de convivência familiar, que em sua nova e constitucionalizada concepção apresenta uma obrigação legal aos genitores e um direito fundamental para os filhos. Em verdade não se sustenta mais que a convivência (visita) seja uma escolha do genitor, e nem um direito exclusivo deste, pois está bem mais relacionada ao bem-estar do filho do que propriamente do genitor. "A convivência familiar para com os genitores está muito mais atrelada a uma obrigação de fazer, a um ato positivo em face da criança do que propriamente a um direito [...]" (MORAES; VIEIRA, 2020, p. 738-739).

Daí a importância da efetivação da convivência familiar, pois será por intermédio deste relacionamento, desta troca de afeto, em suma desta experiência familiar com ambos os genitores, que a criança e o adolescente poderão criar e desenvolver a ideia de pertencimento e de segurança. A convivência lhe proporcionará um ambiente saudável para o crescimento e desenvolvimento integral, ainda na consolidação de sua personalidade. (TEIXEIRA; TEPEDINO, 2020).

Nessa perspectiva, de fundamentalidade do direito à convivência familiar, é que se compreende que, os direitos fundamentais irão, de fato, incidir no direito privado, independentemente de seu ramo, e "não apenas em relações jurídicas patrimoniais, mas também em relações existenciais" (EHRHARDT JÚNIOR; TORRES, 2018, p. 350). No momento em que se estabelece a convivência familiar como um direito fundamental de ordem constitucional, também deve se estabelecer meios para sua proteção e efetivação, a fim de preservá-los e tutelá-los mediante atuações judiciais, administrativas e legislativas.

Sobre a família e sua essencialidade na formação da pessoa, Hironaka (2018), elucida que:

É inegável que o seio da família forma os que dela participam. É nela que a pessoa se prepara ou é despreparada para a vida gregária, despoluindo ou recebendo obstáculos no caminho entre seu espaço privado e o espaço público. Mais do que simples pessoas, o objetivo da família é formar cidadãos, não apenas das suas cidades e respectivos países, mas do mundo, para que respeitem a dignidade alheia e tenham a si próprios respeitados. É essa a responsabilidade da família: servir, prover e educar (HIRONAKA, 2018, p. 326).

Por este fato é que, cabe aos pais precipuamente estruturarem e amoldarem a personalidade dos filhos, por meio do compartilhamento dos deveres parentais, e no exercício efetivo de seus papeis no desenvolvimento humano da prole (BOSCHI, 2005). No momento em que 
se reconhece as diferenças e complementaridade das funções e das relações parentais, é possível então que a família atinja sua finalidade em ser tempo/espaço no desenvolvimento da personalidade dos filhos, e de forma reflexa também dos adultos, devendo estas funções e ações serem respaldadas pelo afeto, pela responsabilidade e solidariedade. (GROENINGA, 2009).

Embora se garanta o direito ao livre planejamento familiar a todas as pessoas, estas não estão isentas das obrigações envoltas às responsabilidades de cuidado e zelo para com a criança, cabendo aos pais independentemente de sua vontade, prover a assistência moral, material, afetiva, intelectual e espiritual aos filhos desde sua concepção (CARDIN; SANTOS; GUERRA, 2015). Assim, o direito à convivência familiar "não se estrutura como objeto de prazer pessoal dos genitores, predispondo-se, como dever, à tutela de necessidades próprias do desenvolvimento adequado da personalidade dos filhos [...]" (STRANGER, 1991, p. 58).

Nas palavras de Amarilla (2014):

[...] o direito à convivência familiar deve ser encarado como meio e não como fim em si mesmo, consubstanciando instrumento vocacionado ao desenvolvimento da personalidade de seus membros e atendimento das demandas especiais daqueles que, em razão de sua pouca idade insuficiente maturidade, clamam por mais atenção e cuidado (AMARILLA, 2014, p. 90).

Será a efetiva convivência que irá estabelecer o afeto necessário para a vida digna da criança e do adolescente, daí a importância de se respeitar este direito, sempre tendo em vista os Direitos da Personalidade tanto dos filhos quanto dos pais (GROENINGA, 2009). Nesta linha de pensar Moraes e Vieira (2020, p. 752) sustentam que: "[...] a convivência familiar saudável e duradoura possibilita à criança efetivar o direito a sua integridade psicofísica, à honra, ao respeito e ainda ao livre desenvolvimento de sua personalidade". Assim, será na família e nesta relação e interação que será promovido o desenvolvimento da personalidade e potencialidade de seus membros, garantindo-Ihes assim, o respeito da dignidade da pessoa humana neste aspecto social. (GAMA, 2008).

Ademais, o direito à convivência familiar se perfaz como um direito fundamental que visa garantir a proteção de outros direitos, mais especificamente os da personalidade, direitos estes que são "inerentes à pessoa e à sua dignidade" (TARTUCE, 2017, p. 153). É através da convivência que se estabelecerá a integridade física e psíquica do filho, é por meio da convivência que se terá o respeito e cuidado para com seus direitos existenciais da criança e do adolescente.

Esta interação física e emocional entre o filho e ambos os genitores é imprescindível para que se implemente os inúmeros direitos fundamentais e da personalidade do filho, servindo a convivência como um instrumento que beneficia o pleno desenvolvimento biopsicossocial da criança e adolescente (BOSCHI, 2005). Não bastando assim prover apenas o sustento e educação, "mas é preciso garantir a convivência dos filhos com os pais, entendendo-se essa convivência como fundamental para a formação da personalidade no indivíduo" (ANGELINI NETA, 2016, p. 85).

O ambiente familiar como já elencado, tem grande influência no desenvolvimento infantojuvenil, devendo os pais garantir-lhes ao menos o mínimo de condições para que ocorra o desenvolvimento da personalidade dos filhos (TOMASZEWSKI, 2004), pois quando isso não ocorre, direitos serão violados, danos serão causados e a dignidade será maculada. Quando 
existe a falta de zelo, cuidado e afeto nas relações paterno-materno-filial, pode-se dizer que desencadearão "incontroláveis danos pessoais e sociais" (JABUR, 2019, p. 1115).

A omissão no que se refere ao convívio e contato físico e emocional com o filho é uma violação direta a este direito fundamental, mas, além disso, é uma violação reflexa à inúmeros direitos da personalidade previstos do tanto na Constituição Federal de 1988, como no Código Civil de 2002. "A título exemplificativo tal ato viola os direitos da personalidade na esfera física (direito à vida, integridade física), psíquica (direito à liberdade, integridade psíquica) e moral (direito à identidade, respeito)" (MORAES; VIEIRA, 2020, p. 750).

Caso não venha existir a convivência familiar, o filho poderá carregar consigo o sentimento de abandono, traumas de rejeição, dificuldades de se relacionar e ainda inúmeros outros danos que irão variar sua intensidade de pessoa para pessoa ${ }^{3}$. Quando ausente os estímulos necessários a pessoa humana em desenvolvimento, "todo um aspecto capital da personalidade da criança, de sua 'humanidade', poderíamos dizer que já mais se constituiu" (TOMASZEWSKI, 2004, p. 86).

Logo, quando o genitor se nega em conviver com seu filho, sendo omisso em seus deveres, vem a ocasionar danos de ordem extrapatrimonial. Nestes termos, Basset (1993) elucida que:

Cuando el progenitor no convivinte se niega injustificadamente a contribuir consu figura paterna o materna, en forma visible, edecuada y positiva, su conducta viola um derechoe sencial del hijo, de cuya formación sana y integral es responsable, incurre em una acción u omisión ilícita que puede ocasionar daños extrapatrimoniales y materiales, que um imperativo de justicia exige reparar. (BASSET, 1993, p. 27-28)

Desta forma, é possível dizer que a concretização dos direitos fundamentais e da personalidade em primeiro momento incumbe ao Poder Judiciário, posto que muitas vezes políticas públicas organizadas pelo Estado, não conseguem alcançar seu fim preventivo e promocional (FERIATO; MARCH, 2019). Por este fato que é se compreende que independentemente da vontade do genitor que não convive cotidianamente com a prole, deve cumprir com seus deveres legais, mesmo que em seu âmago não queira exercê-la, por motivos que o direito não pode abarcar.

Por fim coloca-se que, o direito à convivência familiar é um direito fundamental do filho que possuí uma função instrumental de efetivação de outros direitos fundamentais e da personalidade, bem como impõem aos genitores obrigações legais envolvendo conviver e cuidar. Quando existe a omissão parental no que tange a convivência seja ela total ou parcial, fala-se então em um dano existencial imensurável pelo Direito, incumbindo-se então ao Poder Judiciário de efetivá-lo a fim de garantir o melhor interesse da criança e a sua proteção integral.

3 Nesse sentido coloca-se que: "Esses pais omissos no dever de visitar o filho acabam causando-lhe prejuízos de ordem moral e psicológica irreparáveis. A convivência que o pai furtou do filho, as emoções que não foram compartilhadas, o vínculo afetivo que não se formou ou não se manteve não poderão ser recuperados, por total impossibilidade de retroação no tempo" (BOSCHI, 2005, p. 213). 


\section{DO TÍTULO EXECUTIVO JUDICIAL E O CUMPRIMENTO DE SENTENÇA DO DIREITO À CONVIVÊNCIA FAMILIAR}

Vivencia-se nos atuais dias uma onda de relacionamentos, e muitos destes acabam por ocasionar no nascimento de outro ser humano. Independente do estado civil destas pessoas, filho sempre será filho, e cabe aos pais, estejam eles juntos ou não, prover todas as necessidades desta prole 4 . "A separação dos cônjuges (separação de corpos, separação judicial ou divórcio) não pode significar separação entre pais e filhos. Em outras palavras, separam-se os pais, mas não estes em relação aos seus filhos menores de 18 anos" (LÔBO, 2008, p. 168).

Logo, por não existir o desfazimento dos deveres e responsabilidades parentais, estes independentemente de seu estado civil, ou relacionamento amoroso, terão o dever de amparar os filhos, principalmente em seu aspecto imaterial. E será por intermédio da convivência familiar que estes deveres irão ser materializados. Desta forma, a efetivação dos deveres parentais no que se restringe a convivência familiar vai além de estar fisicamente junto com o filho, mas nota-se na materialização de um conjunto de ações que se destinam na proteção, zelo e cuidado da criança e adolescente, compondo assim, um feixe de condutas que tem como primado o melhor interesse do vulnerável.

O direito à convivência familiar traz consigo uma perspectiva bilateral, onde tanto os genitores como os filhos são detentores deste. E pelo fato de que este direito contribui para a satisfação das necessidades da prole, é preciso existir mecanismos que possam assegurar a sua satisfação, que tem como maior beneficiário a criança e adolescente. (TARTUCE, 2019).

O genitor que não reside de forma habitual com sua prole terá especial responsabilidade da efetivação da convivência familiar. Incumbe-se a este encontrar meios para melhor se realizar este tempo de relacionamento, adequando os horários, dias, e atividades que serão desempenhadas, buscando-se fortalecer este vínculo e assim garantir o pleno desenvolvimento da personalidade do filho. (BOSCHI, 2005).

É somente por intermédio da compreensão de que a convivência familiar é um direito infantojuvenil, vinculado à pessoa vulnerável, e não mais uma obrigação simplesmente moral dos pais, que será possível abrirem espaços para o debate e discussão sobre uma tutela jurídica voltada para este instituto, e formas de resgate e promoção de uma parentalidade responsável (MORAES; VIEIRA, 2020). "Por isso, não pode o visitante, desde que fixada a visita, negligenciar o dever de efetuá-la, deixando de cumpri-la na forma acordada, sob pena de sua omissão caracterizar atentado a direito fundamental do visitado (art. $5^{\circ}$ do ECA)" (BOSCHI, 2005, p. 209).

As relações familiares da contemporaneidade muitas vezes são formadas sem que haja o real sentido da afetividade, da solidariedade e ainda da consciência de uma parentalidade responsável e respeito à dignidade humana (CARDIN; SANTOS; GUERRA, 2015). O que acaba por muitas vezes em ocasionar no descumprimento dos termos elencados no título executivo judicial, em especial os pontos relativos à convivência, visto que por motivos subjetivos o genitor não guardião acaba por inadimplir com seus deveres parentais.

4 Sobre tal fato social, Grisard Filho (2010, p. 196) sustenta que: "É fato por todos conhecido que dia a dia aumenta o número de rupturas familiares e cresce a formação de novos núcleos, nos quais convivem ou circulam e se socializam filhos de distintas uniões, constituindo uma rede de sustento material e emocional não isenta de antagonismos e conflitos". 
Como exposto, é direito da criança e do adolescente poder se desenvolver em todos os seus aspectos (moral, espiritual, psíquico, físico, entre outros), sendo a adequada e contínua convivência familiar que lhe proporciona este desenvolver. Nesse sentido, "não bastará ao vencedor, no entanto, a emissão da ordem. É preciso que seja cumprida no mundo real" (ASSIS, 2013, p. 174). Assim, "[...] não é totalmente descabido exigir daqueles que comungam do direito de visitas, especialmente os pais, o cumprimento em favor do menor; afinal, este também é titular do direito à convivência" (TARTUCE, 2019, p. 434).

Nestes termos, Dias (2017, p. 565) compreende que: “É muito mais um direito do filho de conviver com o genitor que não detém sua guarda. Assim, há uma obrigação - e não simples direito - dos pais de cumprirem os honorários de visitação". Uma vez que se regulamente a forma de convivência familiar, o genitor não guardião, aquele que não reside com o filho de forma habitual, possui um dever legal, que tem sua gênese um acordo homologado em juízo ou ainda uma decisão judicial, portanto, a convivência familiar "passa a decorrer de lei entre as partes, de uma norma individual" (BOSCHI, 2005, p. 210).

Dessa forma, ocorrendo o descumprimento de sentença, ou acordo, este genitor "poderá ser responsabilizado pelos danos morais e patrimoniais daí advindos ao visitado" (BOSCHI, 2005 , p. 210). Mas além destas penalidades, deve-se também garantir meios de cumprimento, mesmo que forçado, à devida e adequada convivência familiar ao filho, uma vez que, é um dever legal e não moral ${ }^{5}$.

Nestes termos, Tartuce (2019, p. 434) sustenta que: "Impor o cumprimento forçado das visitas não gera, por si só, prejuízo ao menor. 0 genitor estará presente, e o filho não se sentirá rejeitado. Caso haja receio quanto a eventuais maus-tratos, a convivência pode ser monitorada". Os filhos podem e devem exigir a devida convivência e cuidado de seus pais ou responsáveis, posto que, quando não cumpridos de forma espontânea,além culminar da possibilidade de reparação civil, dependendo do caso pode ocorrer a supressão do poder familiar fundamentado na negligência de seu exercício. (JABUR, 2019).

No momento em que se garantem direitos, e sendo um deles o de acesso à justiça, é preciso pensar que além deste, faz-se necessário ter uma efetiva prestação jurisdicional. Assim, em nada adianta o Estado dizer o direito, se não é capaz de protegê-lo e/ou efetivá-lo de maneira justa (CASAGRANDE; TEIXEIRA, 2019). Em outras palavras, em nada adianta à pessoa do filho ter seu direito regulamentado em título executivo judicial se este não pode ser cumprido quando existir a resistência do genitor em adimplir com sua obrigação de fazer (conviver).

O Processo Civil é a forma que se tem hoje para a efetivação dos direitos materiais concebidos na ordem jurídica, e é por meio do Código de Processo Civil de 2015 - Lei n. 13.105/2015 - que se organiza este procedimento executório que objetiva a satisfação de uma obrigação determinada em título executivo judicial ou extrajudicial.

5 Recurso Especial. Civil e Processual Civil. Regulamentação de visitas. Acordo homologado. Descumprimento. Execução. Cabimento. 1. No campo das visitas, o guardião do menor é devedor de uma obrigação de fazer, ou seja, tem o dever de facilitar a convivência do filho com o visitante nos dias previamente estipulados, devendo se abster de criar obstáculos para o cumprimento do que fora determinado em sentença ou fixado em acordo. 2. A transação, devidamente homologada em juízo, equipara-se ao julgamento do mérito da lide e tem valor de sentença, dando lugar, em caso de descumprimento, à execução da obrigação de fazer, podendo o juiz, inclusive fixar multa a ser paga pelo guardião renitente. 3. Recurso especial conhecido e provido a fim de determinar o retorno dos autos ao juízo de primeiro grau para regular prosseguimento. (STJ. REsp. n. 701.872-DF. Quarta Turma. Relator: Ministro Fernando Gonçalves. Julgado em 12.12.2005). 
Normalmente a convivência familiar, por se tratar de direito de pessoa vulnerável, estará disposta em título executivo judicial (art. 515, CPC), seja este proferido em sentença ou até mesmo em acordo realizado pelas partes, homologado pelo juízo competente. Que seguirá o procedimento do Cumprimento de Sentença que Reconheça a Exigibilidade de Obrigação de Fazer ou de Não Fazer, estipulado no art. 536 a 537 do Código de Processo Civil de 2015. (BRASIL, 2015).

Sobre o tema, Madaleno (2019) coloca que:

A doutrina e jurisprudência têm entendido o direito de visitas como um dever passível de execução judicial, inclusive pela imposição de multa pecuniária através das astreintes, sendo certo que os pais têm o dever de contato para com seus filhos e se, porventura se olvidam dessa obrigação, por egoísmo ou vingança contra o outro genitor, seu ex-parceiro afetivo, [...] sendo salutar que o Estado-juiz force, através de ameaça financeira, os progenitores sem a guarda a exercerem o dever de convivência, pois só desse modo podem se dar conta de que existem outras formas de destilar seu ódio pelo amor conjugal que se desfez. (MADALENO, 2019, p. 475-476)

0 processo de cumprimento de sentença é iniciado quando não existe o adimplemento das determinações elencadas em título executivo judicial de forma espontânea. Título este que é um documento típico que garante ao detentor direito a determinada prestação (certa, líquida e exigível - art. 783, CPC), autorizando-se caso não cumprido, o início da tutela jurisdicional de natureza executiva, que tem como principal característica a prática coativa de atos materiais, que objetivam proporcionar o adimplemento forçado da prestação. (GARJARDONI; et al., 2018).

Pelo fato da efetivação da convivência familiar depender quase que exclusivamente do cumprimento da obrigação de fazer do genitor não guardião, o título executivo não se mostra autossuficiente, na medida em que o direito assegurado depende de uma prestação por parte do demandando, necessitando-se assim de uma tutela executiva, para que assim haja o adimplemento pelo executado (GARJARDONI; et al., 2018). "O direito de convivência gera uma obrigação de fazer infungível, obrigação personalíssima, que deve ser cumprida pessoalmente" (DIAS, 2017, p. 566).

O Poder Judiciário pode utilizar-se de medidas coercitivas (multa periódica) - que "tem e deve ter, no âmbito do Direito de Família, caráter desestimulador do inadimplemento das obrigações assumidas" (MIGUEL FILHO, 2006, p. 818) - ou de sub-rogação (busca e apreensão ou a reintegração de posse) para que assim consiga prestar ao exequente a devida tutela executiva, todavia, no caso envolvendo descumprimento da convivência, resta-se apenas a possibilidade de aplicação de astreinte ${ }^{6}$, com fundamento no art. 213 do Estatuto da Criança e do Adolescente - Lei n. 8.069/90 -, visto que somente o genitor poderá cumprir com esta obrigação e ninguém mais. (BRASIL, 1990).

Sobre a aplicação de multa diária envolvendo o descumprimento da convivência com os filhos, Teixeira e Tepedino (2020, p. 318) esclarecem que:

6 Execução de obrigação de fazer. Visitas. Multa. Tendo o magistrado determinado que em caso de descumprimento do acordo de visitas seria imposta multa à virago e tendo ela, mesmo ciente da decisão, ignorado a determinação, correta se mostra a indenização fixada. Até porque, não trouxe ela nenhum fundamento plausível que faça com que seja elidido o pagamento da multa. Apelo desprovido. (TJ/RS. Sétima Câmara Cível. Apelação Cível n. 70.012.800.207. Relatora: Des. ${ }^{\text {a }}$ Maria Berenice Dias. Julgado em 21.12.2005). 
Uma das possibilidades para compelir um dos pais a conviver com os filhos é a imposição de multa prevista nos arts. 497 e ss. do CPC, quando se entende que a convivência é obrigação de fazer, pois é através dela que se concretizam inúmeros deveres decorrentes da autoridade parental, como a educação e a criação. No entanto, critica-se a solução na medida em que induz à monetarização das relações familiares e nem sempre o convívio imposto será melhor para o filho. Embora a multa tenha sido prevista como penalidade ao genitor alienador pelo art. $6^{\circ}$, III, da Lei 12.318/2010 (acabando com o argumento de que as relações familiares seriam misturadas às questões financeiras), sua função nesses casos é de coação para o cumprimento das cláusulas de convivência estabelecidas judicialmente (por acordo, decisão interlocutória ou sentença). (TEIXEIRA; TEPEDINO, 2020, p. 318).

O valor pecuniário da multa diária não é o foco a execução, em verdade é apenas o meio disponível para tentar se conseguir a realização da obrigação de fazer, assim, tal medida tem como fim "constranger o devedor a não inadimplir, ou seja, a cumprir a obrigação assumida. E não é de natureza punitiva do inadimplemento" (MIGUEL FILHO, 2006, p. 819).

Consiste basicamente em uma pressão psicológica exercida ao executado, colocando-o perante dois cenários: ou cumpre o comando judicial ou sofrerá a aplicação de multa (astreinte) (ASSIS, 2013).“Ou seja, pensa-se na prática coativa de atos materiais que visam a proporcionar a satisfação forçada de uma prestação devida e inadimplida, a conformar o mundo externo à determinação constante no título executivo judicial" (GARJARDONI; et al., 2018, p. 672).

Diferentemente da execução alimentar que possui a possibilidade de utilizar-se a ameaça de prisão (art. 528, $\S 3^{\circ}, \mathrm{CPC}$ ), bem como os meios expropriatórios (penhora) (art. 528, $\S$ $\left.8^{\circ}, C P C\right)$, a execução da convivência familiar somente dispõe deste mecanismo de execução indireta, que é a multa em dinheiro (astreinte). (BRASIL, 2015).

Sobre tal questão, Amarilla (2014, p. 205) elenca que:

No que concerne à pratica da parentalidade, entende-se que poderá o Estado constranger pais e mães a prestarem todo o apoio material necessário à prole, sempre com vistas na tutela integral dos interesses de crianças e adolescentes. Entretanto, deve-se ressaltar que o suporte material não proverá o prole daquilo que ela mais necessita, pois o vínculo mais profundo e significativo que se pode conceber para um filho quanto ao seu pai e mãe [...].(AMARILLA, 2014, p. 205).

Como bem se sabe, tal ferramenta de coerção acaba por ser ineficaz quando o executado não tem patrimônio a ser penhorado. Sobre este ponto, Assis (2013, p. 176) preceitua acerca desta "falha" que permeia o processo de execução, "[...] e consiste no fato de não induzir ao cumprimento o destinatário da ordem desprovido de patrimônio penhorável". Desta forma, o genitor que se negar a realizar a convivência, se não tiver patrimônio para responder, a fixação de astreinte em nada mudará sua atitude, que continuará de inércia em face da criança e/ou adolescente.

O processo não é apenas uma garantia individual, mas também é considerado como um direito fundamental transcendental, que objetivam ações estatais positivas (KNOPFHOLZ, 2011). Quando o processo não alcança o fim que é almejado, fala-se então de um processo executivo infrutífero. Mas ao se colocar um direito fundamental, essencial e estruturante para a pessoa, direito este que é o da convivência familiar, o Estado não pode ficar inerte, sob 
pena de violar seus próprios fundamentos. "Compreendem-se, nesta situação, as complexas causas da grave crise presente da função executiva" (ASSIS, 2013, p. 13).

O tratamento simplista que o Judiciário continua dando para as questões relativas à reorganização das relações entre pais e filhos ocasionam uma crise em face da efetivação dos direitos infanto-juvenis (GROENINGA, 2009). "É claro que o Poder Judiciário não pode deixar de tutelar os direitos dos detentores de uma pretensão, ou deixar passar em branco os casos de irresponsabilidade parental" (CARDIN; SANTOS; GUERRA, 2015, p. 142). Todavia, esperar que se tenha configurado o abandono afetivo, e consequentemente danos irreparáveis a criança e adolescente, e crer que somente as indenizações resolverão os problemas de ordem psíquica e estrutural da pessoa, é uma violação direta a Constituição Federal e aos valores internacionais de respeito e promoção dos Direitos Humanos.

O que se evidencia atualmente é que o processo de cumprimento de sentença, que visa o adimplemento da convivência familiar, possui um tratamento superficial, aplicando-se "remédios" (astreinte), que tornam muitas vezes ineficazes em sua aplicação. "O remédio, no entanto, age apenas sobre a ferida, não atacando a causa" (SPENGLER, 2006, p. 51).

A ideologia patrimonialista que marcou a codificação de 1916 ainda se encontra presente no Código Civil de 2002 e reflete diretamente no Código de Processo Civil de 2015, entretanto, esta não pode prevalecer sobre os valores existenciais que emanam da Constituição Federal de 1988, sob pena de acarretar em uma inversão sistemática e axiológica (SCHREIBER, 2016). "As legislações processuais vigentes em nosso ordenamento, inclusive a novel de 2015, têm caráter estritamente patrimoniais e são, em essência, burocráticas, 0 que inviabiliza uma tutela efetiva destes direitos etéreos" (MEDINA, 2017, p. 40).

Já se encontra pacificado nos tribunais a possibilidade de reparação civil quando constatada a negligência ou recusa ao dever de cuidado. Nesse sentido, o não fazer, a omissão parental reiterada e injustificada no que se refere à convivência familiar por parte do genitor não guardião, poderá constituir motivo de responsabilização por danos morais infringidos ao filho. (BOSCHI, 2005).

Sobre as questões levantadas, Basset (1993) entende que:

Toda acción u omisión violatoria total o parcialmente de los derechos-deberes subjetivos familiares que emergen del vínculo filiatorio, que cause adecuadamente daños, Sean éstos de naturaleza extrapatrimonial o patrimonial, debe obligar a reparar. El derecho no puede permanecer impasible ante uma paternidad o maternidad irresponsable, consagrado una inmunidad que ponga a cubierto al progenitor claudicamente de sus deberes, de la obligación, frente al daño causado, de resarcir lo íntegramente, aunque este calificativo se presente em la realidad histórico-vivencial del damnificado como una utopia. (BASSET, 1993, p. 228-229)

Todavia, a indenização pecuniária nestes casos de abandono afetivo, ou ainda a aplicação de multa diária pelo descumprindo do convívio, não deixa de carregar traços de ordem capitalista, "no sentido de que com a condenação, a pessoa aufere um valor para compensar ou amenizar um mal sofrido, fato este que aumenta demasiadamente a demanda judiciária sem, realmente, solucionar o problema" (CARDIN; SANTOS; GUERRA, 2015, p. 142).

O problema que assola a efetividade processual, está relacionado à sua interpretação e aplicação. O Processo é um instrumento a favor do Poder Judiciário para a resolução de 
conflitos, e para que este tenha sua efetividade de forma satisfatória, não se pode deixar de lado que o Processo (e o Direito) é uma identificação cultural, e precisa então ser aplicada a luz do tempo e realidade que se esta (MÖLLER, 2029). "Vive-se uma verdadeira crise social e jurídica que afeta inúmeras instituições da sociedade, sendo a família a principal atingida por esse fenômeno" (CARDIN; SANTOS; GUERRA, 2015, p. 132).

A forma de tratar o direito de convivência familiar é em sua totalidade inadequada e insuficiente. Demonstrando-se que, os meios técnicos legislados e legalmente possíveis no processo de execução ainda não evoluíram suficientemente para garantir assim, a efetiva tutela jurídica. (ASSIS, 2013).

Compreendendo-se estas questões envoltas a insuficiência processual, nota-se que o processo civil necessita de uma maior abertura cognitiva voltada à para a tutela dos direitos, para que assim consiga responder de forma não simplista as complexidades do mundo. 0 processo precisa ser observado a partir de sua complexidade e importância, em síntese, possibilitar a este, meios que consiga dar uma resposta satisfatória frente às diversidades sociais que deságuam no judiciário a cada dia. (MÖLLER, 2029).

Resta claro que existe uma limitação dos mecanismos processuais em face da efetivação do regime de convivência familiar estipulado (TARTUCE, 2019). Contudo, tais limitações não podem ser óbice para a efetivação ou pelo menos a tentativa de concretização do direito fundamental da criança e do adolescente.

Desta forma, "o Direito de Família exige rapidez na solução de seus conflitos, pois o dissabor suportado pelas partes envoltas a pendenga causa tanta amargura que um processo moroso em nada ajudará, muito pelo contrário" (BEZERRA; SOARES, 2019, p. 72). 0 acesso à justiça, não abarca somente o seu sentido literal, mas abrange também ter o direito a um devido processo, processo este que precisa respeitar as garantias individuais e ainda consiga produzir uma decisão eficaz. (CASAGRANDE; TEIXEIRA, 2019)

Como já sustentando, é possível a imposição do pagamento de multa diária para o genitor que descumprir com seu dever de convivência, e ainda na fixação de indenização ao genitor que for omisso as suas obrigações de cuidado, que acabam por violar direitos fundamentais e da personalidade da criança e do adolescente. Contudo, também se sabe que, tais decisões por si só não solucionam os problemas familiares em sua fonte.

Por estes motivos, precisa-se repensar o processo, as medidas coercitivas, bem como a forma de tratamento dos conflitos familiares, ultrapassando a visão patrimonialista predominante na legislação material e processual, para se, ao menos, tentar proteger direitos subjetivos, existenciais e estruturantes da pessoa humana.

\section{DA CONCEPÇÃO FILHOCENTRISTA E A NECESSIDADE DE UMA ALTERAÇÃO PROCEDIMENTAL E NORMATIVA}

A modificação e reestruturação familiar não apenas mudou a forma de tratamento, mas também colocou a criança e o adolescente no topo, como primeiro e mais importante mem- 
bro da família, visando que tenham suas necessidades atendidas de forma integral e satisfatória.

Rompeu-se com a antiga noção de pertencimento (relacionada à propriedade) do genitor (normalmente a figura masculina da relação), ocasionando assim, no reposicionamento dos filhos para o centro de qualquer discussão jurídica (AMARILLA, 2014). Posto isto, "com os novos contornos, traçados a partir do princípio da dignidadehumana, a criança e o adolescente passaram a ser percebidos de forma diferenciada no agrupamento familiar" (BRETAS; OLIVEIRA, 2019, p. 47).

Sobre a temática Grisard Filho (2016, p. 46) elucida que: "O que existe é uma uniforme concepção filho centrista, que desloca o seu fulcro da pessoa dos pais para a pessoa dos filhos [...]". Em outras palavras, a concepção do filho centrista veio a prestigiar o filho dentro desta relação familiar, incumbido aos pais a observância, respeito e promoção dos direitos destes.

Esta nova concepção voltada para as relações familiares se justifica na medida em que os filhos são pessoas vulneráveis, "visto que podem ser oprimidas de diversas formas possíveis, como por exemplo, na falta de exercício da parentalidade responsável retratada pela rejeição ou pela violência intrafamiliar [...]" (MORAES; ROSA, 2017, p. 39). As questões envoltas à proteção da criança e do adolescente passam a ser tratadas como um problema supraindividual e internacionalizado. (MARQUES; MIRAGEM, 2012).

Os princípios voltados para o Direito das Famílias sofreram em sua totalidade uma releitura, voltando-se para a proteção e bem-estar da criança e do adolescente, e de forma subsidiária dos outros membros. Em resumo, os princípios agem como verdadeiras normas impositivas a serem aplicadas em sua maior extensão possível, variando caso a caso.

A aplicação principiológica diante do caso concreto se faz imperiosa e necessária, tendo em vista que, este arcabouço protetivo contribui "para a efetivação do pleno desenvolvimento da personalidade dos membros da família e à proteção de seus direitos da personalidade" (BARRETO; CARDIN, 2007, p. 304). Direitos estes que nos dizeres de Tartuce (2017, p. 153) possuem como objetivo "os modos de ser, físicos ou morais do indivíduo e o que se busca proteger com eles são, exatamente os atributos específicos da personalidade, sendo personalidade a qualidade do ente considerado pessoa".

Compreende-se que os princípios constitucionais mostram um caminho a seguir, limites a serem observados e ainda, um mínimo a ser respeitado diante da ponderação e proporcionalidade, daqueles que são em suma os direitos fundamentais e da personalidade (BARRETO; CARDIN, 2007). Coloca-se que, independe o ramo do direito seja ele público ou privado, todos sofrem influência da Constituição e dos preceitos internacionais de proteção da pessoa humana.

Nesta lógica, o direito processual civil também deve se pautar nos princípios constitucionais voltados à proteção das crianças e adolescentes. Uma vez que os preceitos constitucionais são a base do Estado Democrático de Direito e que objetiva a valorização do ser humano (CAMARGO; JACOB, 2020). "O direito processual, ramo do direito público, é regido por normas que se encontram na Constituição Federal e na legislação infraconstitucional" (NERY JUNIOR, 2017, p, 56). 
$\mathrm{O}$ individualismo exacerbado e a liquidez dos relacionamentos colocam em risco os direitos fundamentais e da personalidade da pessoal vulnerável dentro da relação familiar, pois sem a devida entrega e amparo dos genitores, o filho não conseguirá desenvolver plenamente a sua personalidade, vindo assim, a ensejar um mal para toda sociedade, que somente maximiza esta crise da pós-modernidade. (CARDIN; SANTOS; GUERRA, 2015).

Neste ponto, independe o sentimento que o genitor nutra pelo filho, a convivência familiar é um direito fundamental para o desenvolvimento da criança e do adolescente, logo não pode sua efetivação ficar refém das vontades e desejos subjetivos do genitor não guardião. Tal afirmação se sustenta sob o primado da dignidade humana e atuais valores jurídicos. (MORAES; VIEIRA, 2020).

Como já colocado, a responsabilidade civil aplicada às questões envolvendo o cuidado parental somente prevê a condenação pecuniária, ou ainda, a multa diária aplicada pela inadimplência do convívio regulamentado, que como bem sabe, não repara o dano causado, apenas poderá proporcionar uma amenização do dano, através do pagamento de terapia. "Na perspectiva da plena reparação da vítima, o filho, que teve sua integridade psíquica violada - e, em última instância, a sua dignidade - continua sem nenhum tipo de compensação pelo dano sofrido" (TEIXEIRA; TEPEDINO, 2020, p. 298). Visto que, o que se almeja é o convívio, o cuidado, o zelo e não dinheiro, quer-se ter um pai e uma mãe, não números em uma conta bancária.

Assim, necessita-se de uma atuação jurisdicional muito mais criativa, sensível e capacitada para as resoluções de conflito, mesmo que em fase de execução, visto que, pode o juiz, com fundamento no art. 139 do Código de Processo Civil de 2015, vir a adotar medidas coercitivas atípicas (inciso IV), incentivar a promover a autocomposição (inciso V), ou ainda, determinar, o comparecimento pessoal das partes para tentar entender o motivo de tal resistência no cumprimento da convivência (inciso VIII), entre outras disposições que estão ao seu poder. (BRASIL, 2015).

Sob o tema abordado Bezerra e Soares (2019) elucidam que:

É de extrema relevância que o Poder Judiciário permaneça sempre atuante como ente fiscalizador e protetor dos direitos de família, tendo em vista que qualquer sociedade é estruturada e tem como base para formação do Estado uma família saudável e sem conflitos. Já que os danos causados pela não resolução de litígios entre familiares pode resultar em graves danos irreversíveis à sociedade. (BEZERRA E SOARES, 2019, p. 57)

Enquanto uma lei adequada para o tratamento dos conflitos familiares não vem, incumbe ao Poder Judiciário o dever de suprir as falhas legislativas do atual diploma legal (SCHERBAUM; ROCHA, 2018). Este precisa se aparelhar de ferramentas que fazem fortalecer o ordenamento jurídico, tendo como foco a proteção da pessoa e de suas garantias individuais (FERMENTÃO, 2016). Parece que o Judiciário esquece que "o conflito é um mecanismo complexo, derivado da multiplicidade dos fatores, os quais nem sempre estão definidos na sua regulamentação, não sendo, portanto, apenas normatividade e decisão" (SPENGLER, 2006, p. 34).

Nenhum dispositivo normativo, seja de direito material ou processual, deve ter sua interpretação afastada das imposições e limites fixados pela Constituição Federal de 1988 (CAMARGO; JACOB, 2020). Desta forma, coloca-se que, "o aplicador da norma infraconstitu- 
cional, dentre mais de uma interpretação possível, deverá buscar aquela que a compatibilize com a Constituição, ainda que não seja a que mais obviamente decorra do seu texto" (BARROSO; BARCELLOS, 2003, p. 164).

Sendo necessário romper com antigas concepções e ensinamentos, para que assim, na prática jurisdicional se consiga obter efeitos positivos sobre a realidade (BARROSO; BARCELLOS, 2003). Tendo em vista que, “[...] é somente por meio de uma atuação diferenciada do papel do julgador, a ser obtida por intermédio da atividade hermenêutica, que será possível garantir a efetividade da prestação jurisdicional e a tão almejada 'justiça' nos casos mais complexos" (MEDINA, 2017, p. 84).

Caso se insista na atual formulação processual para o Direito das Famílias, somente se perpetuarãoas situações de insuficiência, violações de direitos e danos irreparáveis, principalmente à pessoa vulnerável desta relação, o filho. Bem se sabe que, a solução do conflito familiar no processo de conhecimento somente vem após um longo processo, que normalmente não vem a pacificar as partes, mas pelo contrário, impõe algo que não soluciona, apenas agride (SPENGLER, 2006). "A decisão judicial de mérito carrega o peso da intervenção estatal, é decorrente deexcessiva duração do processo, contribui para exacerbar a contenciosidade na coletividade,além de contar com a baixa credibilidade da população" (SILVA; CARACIOLA, 2018, p. 447).

Além disso, é comum que, nas relações familiares, o processo judicial seja apenas a parcela mais aparente de um conflito muito mais amplo e profundo, que não é trazido para os autos. A solução imposta pelo juiz às partes, em tais condições, representará uma nova fonte de disputa, que não raro desencadeará novas medidas judiciais, inclusive para obter o cumprimento forçado da decisão anterior. (GARJARDONI; et al., 2018, p. 1177).

Resta-se claro que ao se tratar de questões familiares, o julgador se encontra limitado tecnicamente para apreciar e vislumbrar todas as nuances que permeiam as partes. Pois normalmente os litígios, em fase de conhecimento ou de execução, possuem uma grande carga de sentimentos e histórias. Por este fato é que, "a interdisciplinaridade impõe então ao operador do direito que, consciente dos seus próprios limites, transcenda sua especialidade, acolhendo contribuições de outras disciplinas" (TOMASZEWSKI, 2004, p. 237). Para que as relações familiares conflituosas possam ser adequadamente captadas e compreendidas, se exige o conhecimento especializado, que o juiz geralmente não possui. (GARJARDONI; et al., 2018).

Sendo assim, colocam-se em evidência os profissionais auxiliares da justiça que atuam nas questões psicológicas e sociais. "Nesse sentido, é indispensável à laboração do psicólogo que mediam aos processos no Direito de Família, contemplando os laços afetivos que serão benéficos na evolução da criança" (PEREIRA; ARAÚJO; RIBEIRO, 2020, p. 10). Serão estes profissionais que irão realmente captar possíveis saídas para a resolução dos conflitos familiares, e a partir dos laudos o juiz poderá conceder uma prestação jurisdicional mais particularizada e efetiva. "E a interdisciplina tem tido papel fundamental neste processo de conscientização da complexidade dos relacionamentos e da multideterminação dos conflitos e impasses" (GROENINGA, 2009, p. 154).

O meio consensual já amplamente difundido tanto na prática como na teoria, é a forma mais adequada de resolução de conflitos de natureza familiar, pois estes contribuem para 
que as partes localizem as razões e motivos para as atitudes tomadas, e a partir desta identificação, conseguirem sozinhas solucionar os problemas (TARTUCE, 2019). E ainda, verifica-se que, "meios consensuais são menos impactantes, mais céleres, desburocratizados, e tendencialmente duradouros. Isso por que a composição é alcançada mediante a participação dos interessados, não sendo, pois, imposta coercitivamente" (SILVA; CARACIOLA, 2018, p. 455). Entretanto,em decorrência das constantes situações de conflitos familiares e ofensas aos direitos da criança e do adolescente, é preciso que o legislador brasileiro proporcione uma proteção imediata no que se refere à convivência familiar.

Por estas e outras questões é que o direito deve ser o meio para a realização da justiça, e não apenas ideias legisladas. Para que ocorra efetivamente a justiça, é preciso que se tenha a dignidade humana como seu espelho, objetivo (FERMENTÃO, 2016). Por isso, quando não ocorrer à convivência de forma reiterada e injustificada, se terá a dignidade violada, e imediatamente haverá uma injustiça, que acaba por macular todo o ordenamento jurídico.

Desta forma, Scherbaum e Rocha $(2018$, p. 15) pontuam que:

O direito em si está em constante movimento. Todos os aspectos da vida em sociedade influenciam na criação do direito, da mesma forma que o direito criado influencia diretamente na sociedade. Sob esse mesmo diapasão, é evidente que o direito que emana da sociedade para a sociedade acompanha os fatos, devendo cumprir com as demandas criadas pela sociedade à qual foi criado. (SCHERBAUM; ROCHA, 2018, p. 15)

Diante disto, é evidente que os avanços da sociedade nacional e internacional, fazem com que se coloque em destaque a necessidade de novos instrumentos eficazes para a efetivação da proteção dos direitos existenciais (CASAGRANDE; TEIXEIRA, 2019). Assim, os direitos e garantias voltados às questões jurisdicionais e seu modo de condução - o processo - devem conseguir acompanhar estes avanços. (KNOPFHOLZ, 2011).

Em vista disto, é claro que os litigantes ao se socorrem do Poder Judiciário, possuem certas expectativas em face deste, sendo elas: (a) que seja formulada uma regra jurídica concreta, demonstrando como deverá se dar esta relação - qual deles tem razão; (b) a possibilidade de se fazer valer a regra jurídica imposta ao "vencido", caso este não cumpra voluntariamente; e ainda (c) em situações que demandam certa urgência, a prestação jurisdicional seja rápida e satisfatória (ASSIS, 2013). "A prestação jurisdicional é a essência e a finalidade do Poder Judiciário, um dos pilares do Estado Democrático de Direito. Com ela, o Poder Judiciário se encarrega de resolver lides e conceder tutelas, com o intuito de promover a justiça e a paz social" (FERIATO; MARCH, 2019, p. 300).

O Processo Civil e sua efetividade são necessários à concretização dos diversos direitos fundamentais e da personalidade conferidos às pessoas por intermédio do ordenamento jurídico. Uma lei será mera declaração de intenções se não existirem meios que assegurem o seu devido cumprimento (FERIATO; MARCH, 2019). Em nada adianta a Constituição Federal de 1988, vir a garantir direitos, se, na prática, o Poder responsável, o Judiciário, se encontra desacreditado e ineficiente. (CASAGRANDE; TEIXEIRA, 2019).

Os veículos procedimentais adotados tanto na resolução de conflitos envolvendo direito patrimonial e direito existencial são os mesmos, não existindo distinção. Existe uma nítida deficiência estrutural na legislação processual. "E as medidas executivas, que representam o núcleo das formas de atuação dos direitos, caem na obsolescência" (ASSIS, 2013, p. 13). 
Esta falha faz com que a efetivação do direito à convivência familiar se torne irrealizável. Pois não existe legislado ou ainda um norte para que o julgador "force" o genitor a cumprir com o convívio.

Posto isso, "[...] é necessário superar a ideia de que a perda do poder familiar é a única sanção possível para o genitor que não cumpre os deveres da paternidade" (TARTUCE, 2019, p. 433). Pois esta "sanção" está mais para um prêmio, eximindo o genitor de seus deveres. Afinal, a família é e sempre foi à entidade social responsável pelo desenvolvimento e estruturação da personalidade dos novos cidadãos (CARDIN; SANTOS; GUERRA, 2015), não podendo mais se aceitar posturas omissas, negligentes e danosas voltadas para os filhos. Ambos os genitores são responsáveis, e quando um não cumpre com seu dever, cabe ao Estado fazê-lo cumprir, mesmo que forçosamente.

Com base no exposto, o que se propõe para solucionar as demandas envolvendo o direito à convivência familiar e outros tantos conflitos de natureza familiar, é a implementação de um sistema processual específico, visto que, não se é mais possível continuar com o atual, que mais acaba por violar direitos do que tutelá-los. 0 atual diploma processual tende a tratar conflitos de natureza restritamente patrimoniais e não existenciais. (MEDINA, 2017).

A necessidade de uma legislação processual especifica para os conflitos familiares é de extrema urgência, visto as peculiaridades destes conflitos, e ainda a insuficiência do atual código no tratamento destes. Assim, para que ocorra efetividade no processo de cumprimento de sentença da convivência familiar, é necessária a implementação de meios adequados para tal fim. Sendo apenas possível a proteção da criança e do adolescente quando criados mecanismos que consigam, de fato, solucionar os litígios envolvendo-as e não inflamá-los ainda mais.

Seria conveniente que a nova legislação processual adotasse como medida coercitiva para este tipo de obrigação, além das patrimoniais já existentes. Pensando-se na possibilidade da determinação de seu cumprimento sob pena de incidir no crime de desobediência (art. 330 do Código Penal de 1940) e consequentemente na prisão de 15 (quinze) dias a 06 (seis) meses do genitor executado, e ainda, na aplicação de multa (BRASIL, 1940). Além disso, de forma suplementar e análoga, prever em seu corpo legal que o juiz terá que determinar o acompanhamento psicológico e/ou biopsicossocial tanto do genitor que se nega em realizar a convivência, como da criança e/ou adolescente, nos mesmos moldes do art. 6 da Lei n. 12.318, de 26 de agosto de 2010 que trata sobre a alienação parental.

A formulação de uma legislação processual voltada para o Direito das Famílias, não objetiva violar o princípio da mínima intervenção estatal, nem mesmo ditar uma fórmula pronta e engessada para todas as famílias no que se refere à criação dos filhos. "Porém, um Estado mínimo não significa desconsideração às pessoas, antes, respeito às suas capacidades individuais, como as faces de uma mesma moeda" (GRISARD FILHO, 2010, p. 72).

Cabe ao Estado coibir as agressões a direitos voltados à proteção da dignidade humana, sendo esta a própria razão de existir o Estado - proteção da pessoa, e principalmente dos vulneráveis (FERMENTÃO, 2016). "Para propugnar a concretização de uma paternidade responsável, é essencial que haja instrumentos que signifiquem para o violador do ordenamento uma forma de sanção" (TARTUCE, 2019, p. 433). 
Nas palavras de Boschi (2005, p. 213) "O que se perdeu e o que se deixou de ganhar em termos de amor, carinho, atenção ou assistência não poderá jamais ser restituído". Assim, com esta frase, levanta-se a urgência de mecanismos processuais que efetivamente garantamde forma satisfatória, o cumprimento do direito à convivência familiar, evitando-se a configuração de dano, e consequentemente da necessidade de reparação civil por abandono afetivo, e ainda promovendo uma melhora em toda sociedade.

\section{CONCLUSÓES}

A criança e adolescente são pessoas vulneráveis na medida em que se encontram em um estágio delicado de desenvolvimento. Vislumbrando tal vulnerabilidade a Constituição Federal de 1988 entendeu necessária a proteção desta pessoa, e incumbiu à família, à sociedade e ao próprio Estado na tutela da população infantojuvenil.

Diante dessa proteção, o direito à convivência familiar se mostra como principal direito fundamental desta pessoa em desenvolvimento, pois será por intermédio deste direito que todos os outros irão se realizar. É pela convivência que a pessoa do filho, aprende, cresce e se desenvolve. Sendo assim, um direito principalmente do filho e não dos pais, para esse se consubstancia muito mais como um dever moral, mas principalmente legal, em fazer, realizar a convivência quando não mais existe o vínculo afetivo entre os genitores. Separam-se os pais mais não estes de seus filhos.

Assim, no momento em que existe uma negligência parental, uma omissão no cumprimento da convivência devidamente regulamentada em título executivo judicial, faz-se possível se falar em uma execução forçada. Todavia, o diploma legal que regulamenta o processo civil possui um viés patrimonialista e não existencial, impondo certas limitações ao julgador, que se vê apenas na possibilidade de aplicação de multa diária (astreinte) como medida coercitiva.

Bem se sabe que, quando inexiste patrimônio em nada adianta a aplicação de multa. Desta forma, conclui-se que existe uma insuficiência processual na tutela deste direito fundamental da criança e do adolescente. Precisando-se urgentemente de uma releitura das medidas coercitivas, bem como na condução do processo de cumprimento de sentença, e até mesmo anteriormente, na regulamentação da convivência familiar.

Ciente que existe um problema na tratativa dos conflitos familiares, e que os métodos autocompositivos são a verdadeira salvação para a resolução destes conflitos que em sua grande maioria são de natureza existencial. É responsabilidade tanto do Poder Legislativo como do Judiciário promover cada vez mais estes métodos, de forma adequada e satisfatória, afim de, fomentar o diálogo e não o litígio, que objetiva a resolução de fato do problema e não apenas tratá-lo de forma superficial e inadequada.

Todavia, também cabe a estes mesmos órgãos dar uma solução imediata e em certa medida eficaz para as questões envolvendo o direito à convivência familiar. Podendo-se pensar assim, na possibilidade do Judiciário vir a adotar como medida coercitiva a prisão do genitor não-guardião que não cumprir com a convivência, tendo como fundamento o crime 
de desobediência previsto no art. 330 do Código Penal, bem como determinar que este genitor e a prole, passem por acompanhamento psicológico e/ou biopsicossocial, tendo como objetivo restabelecimento da comunicação e efetivação do direito à convivência familiar.

É evidente a necessidade de uma legislação própria para tratar sobre os conflitos familiares, desde a fase de conhecimento até o processo de execução. Tendo como premissa a proteção e promoção dos direitos infantojuvenis.

No que se refere ao direito à convivência familiar, bem se sabe que, o tempo perdido e os danos causados pela não convivência familiar não são reparáveis com indenização. Por isto é preciso se pensar em formas de evitar o dano, de efetivar a convivência familiar, mesmo que inicialmente forçada, a fim de resgatar este genitor ausente, e promover a sua conscientização sobre seus deveres, e assim, a parentalidade responsável.

\section{REFERENCIAS}

AMARILLA, Silmara Domingues Araújo. O afeto como paradigma da parentalidade: os laços e os nós na constituição dos vínculos parentais. Curitiba: Juruá, 2014.

ANGELINI NETA, Ainah Hohenfeld. Convivência parental e responsabilidade civil: indenização por abandono afetivo. Curitiba: Juruá, 2016.

ASSIS, Araken de. Cumprimento da sentença. 4. ed. Rio de Janeiro: Forense, 2013.

BARRETO, MaíraDe Paula; CARDIN, Valéria SilvaGaldino. Os princípios gerais de direito, os princípios de direito de família e os direitos da personalidade. Revista Jurídica Cesumar-Mestrado, v. 7, n. 1, p. 277-308, 2007. Disponível em: https://periodicos.unicesumar.edu.br/index.php/revjuridica/article/view/527. Acesso em: 09 maio. 2020.

BARROSO, Luis Roberto; BARCELLOS, Ana Paula de. O começo da história. A nova interpretação constitucional e o papel dos princípios no direito brasileiro. Revista de direito administrativo, v. 232, p. 141-176, 2003. Disponível em: http://bibliotecadigital.fgv.br/ojs/index.php/rda/article/view/45690. Acesso em: 09 maio 2020.

BASSET, Lidia N. Makianich de. Derecho de visita. Buenos Aires: Hammurabi, 1993.

BEZERRA, Eudes Vitor; SOARES, Marcelo Negri. Aplicabilidade da tutela antecipada ou cautelar (liminares) no direito de família: instrumentos para a solução dos conflitos familiares. In: MARCÉN, Ana Gascón; [et. al.] (coords.). Direito Civil, de família e constitucional e Gênero, sexualidade e Direito. Zaragoza: Prensas de la Universidad de Zaragoza, 2019. p. 56-75. Disponível em: https://www.conpedi.org.br/wp-content/uploads/2018/04/Vol-21-dir-civil-de-familia-e-consti-genero-sexualidades-e-direito.pdf\#page=57. Acesso em: 05 jun. 2020.

BOSCHI, Fabio Bauab. Direito de visita. São Paulo: Saraiva, 2005.

BRASIL. Lei n 2.848, de 07 de dezembro de 1940. Código Penal. Brasília, DF: Presidência da República, [1940]. Disponível em: http://www.planalto.gov.br/ccivil_03/decreto-lei/del2848compilado.htm.Acesso em: 25 mar.2020.

BRASIL. [Constituição [1988]). Constituição da República Federativa do Brasil. Brasília, DF: Presidente da República, [2016]. Disponível em: http://www.planalto.gov.br/ccivil_03/constituição/constitui\%C3\%A7ao.htm. Acesso em: 05 maio 2020.

BRASIL. Lei n. 8.069, de 13 de julho de 1990. Dispõe sobre o Estatuto da Criança e do Adolescente e dá outras providências. Brasília, DF, Presidência da República, [2019]. Disponível em: http://www.planalto.gov.br/ccivil_03/ leis/I8069.htm. Acesso em: 10 maio 2020.

BRASIL. Lei n. 10.406, de 10 de janeiro de 2002. Institui o Código Civil. Brasília, DF, Presidência da República, [2018]. Disponível em: http://www.planalto.gov.br/ccivil_03/leis/2002//10406.htm. Acesso em: 05 jun. 2020. 
BRASIL. Lei n. 12.318, de 26 de agosto de 2010. Dispõe sobre a alienação parental e altera o art. 236 da Lei no 8.069, de 13 de julho de 1990. Brasília, DF, Presidência da República, [2010]. Disponível em: http://www.planalto. gov.br/ccivil_03/_ato2007-2010/2010/lei/I12318.htm. Acesso em: 13 jun. 2020.

BRASIL. Lei no 13.105, de 16 de março de 2015. Código de Processo Civil. Brasília, DF: Presidência da República, [2015]. Disponível em: http://www.planalto.gov.br/ccivil_03/_ato2015-2018/2015/lei/l13105.htm. Acesso em: 25 mar.2020.

BRETAS, Hugo Rios; OLIVEIRA, Valéria Edith de. O poder familiar em uma visão sistêmica, a partir de um diálogo entre o público e o privado: legitimidade da"palmada" e seus impactos no direito de família e no direito penal. Meritum, revista de Direito da Universidade FUMEC, v. 14, n. 1, 2019. Disponível em: http://www.fumec.br/revistas/meritum/article/view/6038. Acesso em: 16 jun. 2020.

CAMARGO, Carolina Leite de; JACOB, Muriel Amaral. Uma releitura do princípio do acesso à justiça a partir dos novos parâmetros trazidos pelo código de processo civil de 2015. Revista Jurídica Luso-Brasileira [RJLB], ano 6, n. 2, p. 207-231, 2020. Disponível em: https://www.cidp.pt/revistas/rjlb/2020/2/2020_02_0207_0231.pdf. Acesso em: 20 abr. 2020.

CARDIN, Valeria Silva Galdino; SANTOS, Andréia Colhado Gallo Grego; GUERRA, Marcela Gorete Rosa Maia. Dos reflexos da crise do direito liberal na atualidade quando do exercício da parentalidade responsável. Revista Direito e Justiça: Reflexões Sociojurídicas, v. 14, n. 23, p. 131-148, 2015. Disponível em: http://srvapp2s.urisan.tche.br/ seer/index.php/direito_e_justica/article/view/1526. Acesso em: 08 maio 2020.

CASAGRANDE, Jéfferson Ferreira; TEIXEIRA, Rodrigo Valente Giublin. O papel do poder judiciário na contemporaneidade e seu reflexo na dignidade da pessoa humana. Revista Pensamento Jurídico, v. 12, n. 2, p. 375-396, 2019. Disponível em:https://fadisp.com.br/revista/ojs/index.php/pensamentojuridico/article/view/155. Acesso em: 06 jun. 2020.

DIAS, Maria Berenice. Manual de direito das famílias. 12. ed. rev., atual. e ampl. São Paulo: Editora Revista dos Tribunais, 2017.

EHRHARDT JÚNIOR, Marcos Augusto de Albuquerque; TORRES, Marcio Roberto. Direitos Fundamentais e as Relações Privadas: Superando a (Pseudo) Tensão entre Aplicabilidade Direta e Eficácia Indireta para Além do Patrimônio. Revista Juridica, v. 53, n. 4, p. 326-356, 2018. Disponível em: http://revista.unicuritiba.edu.br/index.php/ RevJur/article/view/3222. Acesso em: 08 maio 2020.

FERIATO, Juliana Marteli Fais; MARCH, Giovanna Rosa Perin de. A eficiência nas decisões das tutelas de urgência no Novo CPC para a efetivação dos direitos da personalidade. Revista Brasileira de Direitos Fundamentais \& Justiça, v. 13, n. 41, p. 297-317, 2019. Disponível em: http://dfj.emnuvens.com.br/dfj/article/view/614. Acesso em: 05 jun. 2020.

FERMENTÃO, Cleide Aparecida Gomes Rodrigues. Análise filosófica sobre o princípio da dignidade humana como uma nova teoria de justiça. Revista Jurídica Cesumar-Mestrado, v. 16, n. 3, p. 877-896, 2016. Disponível em: https://periodicos.unicesumar.edu.br/index.php/revjuridica/article/view/5211. Acesso em: 08 maio 2020.

GAJARDONI, Fernando da Fonseca; [et al.]. Processo de Conhecimento e Cumprimento de Sentença: comentários ao CPC de 2015. 2 ed. Rio de Janeiro: Forense; São Paulo: Método, 2018.

GAMA, Guilherme Calmon Nogueira da. Função Social da Família e Jurisprudência Brasileira. In: PEREIRA, Rodrigo da Cunha (org.). Família e solidariedade. Rio de Janeiro: IBDFAM - Lumen Juris, 2008, p. 181-201.

GRISARD FILHO, Waldyr. Famílias reconstituídas: novas uniões da separação. 2. ed. rev. e atual. São Paulo: Editora Revista dos Tribunais, 2010.

GRISARD FILHO, Waldyr. Guarda compartilhada: um novo modelo de responsabilidade parental. 8. ed. rev., atual. e ampl. São Paulo: Editora Revista dos Tribunais, 2016.

GROENINGA, Gisele Câmara. Guarda compartilhada - a efetividade do poder do poder familiar. In: COLTRO, Antônio Mathias; DELGADO, Mário Luiz (coord.). Guarda compartilhada. Rio de Janeiro: Forense; São Paulo: Método, 2009, p. 149-170.

HIRONAKA, Giselda Maria Fernandes Novaes. Direito de família, direitos da personalidade, direitos fundamentais e direitos humanos: correlação entre o ser familiar e o ser humano. Argumentum Journal of Law, v. 19, n. 2, p. 
319-329, 2018. Disponível em: http://ojs.unimar.br/index.php/revistaargumentum/article/view/609/292. Acesso em: 13 maio 2020 .

JABUR, Gilberto Haddad. 0 afeto (ou sua falta) na formação dos filhos: do dever à reponsabilidade. Argumentum Journal of Law, v. 20, n. 3, p. 1.107-1.120, 2019. Disponível em: http://ojs.unimar.br/index.php/revistaargumentum/article/view/1210. Acesso em: 13 maio 2020.

KNOPFHOLZ, Alexandre. As dimensões do processo: análise à luz dos direitos fundamentais. Revista Juridica Unicuritiba, v. 26, n. 10, p. 9-35, 2011. Disponível em: http://revista.unicuritiba.edu.br/index.php/RevJur/article/ view/168. Acesso em: 03 jun. 2020.

LÔBO, Paulo Luiz Netto. Direito Civil: Famílias. São Paulo: Saraiva, 2008.

MADALENO, Rolf. Repensando o Direito de Família. Porto Alegre: Livraria do Advogado. 2007.

MADALENO, Rolf. Direito de Família. 9. ed. Rio de Janeiro: Forense, 2019.

MARQUES, Claudia Lima; MIRAGEM, Bruno. O novo direito privado e a proteção dos vulneráveis. São Paulo: Editora Revista dos Tribunais, 2012.

MEDINA, Valéria Julião Silva. Processo de família e o novo CPC: prática processual versus direito material. Curitiba: Juruá, 2017.

MIGUEL FILHO, Raduan. O direito/dever de visitas, convivência familiar e multas cominatórias. In: Pereira, Rodrigo da Cunha (coord.). Anais de IV Congresso Brasileiro de Direito de Família. Família e dignidade humana. Belo Horizonte: IBDFAM, 2006. p. 811-819.

MÖLLER, Guilherme Christen. O código de processo civil de 2015 e os tempos hipermodernos do processo e da jurisdição. Revista de Processo, Jurisdição e Efetividade da Justiça, v.5, n. 1, p. 81-101, jan/jun., 2029. Disponível em: https://www.indexlaw.org/index.php/revistaprocessojurisdicao/article/view/5534/pdf. Acesso em: 02 jun. 2020.

MORAES, Carlos Alexandre; ROSA, Letícia Carla Baptista. A (in)vulnerabilidade das crianças que advém da realização do projeto homoparental. In: SIQUEIRA, Dirceu Pereira; AMARAL, Sérgio Tibiriçá (org.). Democracia, cidadania e os direitos da personalidade: uma releitura contemporânea. Birigui, SP. Boreal Editora, 2017, p. 36-54.

MORAES, Carlos Alexandre; VIEIRA, Diego Fernandes. O direito de convivência familiar é um direito da personalidade da criança e do adolescente?. Revista Jurídica Luso-Brasileira [RJLB], ano 6, n. 1, p. 733-758, 2020. Disponível em: https://www.cidp.pt/publicacao/revista-juridica-lusobrasileira-ano-6-2020-n-1/203. Acesso em: 20 fev. 2020.

NERY JUNIOR, Nelson. Princípios do processo na Constituição Federal. 13. ed. rev., atual. São Paulo: Editora Revista dos Tribunais, 2017.

PEREIRA, Irving Rahy de Castro; ARAÚJO, Marcella Bezerra; RIBEIRO, Maura Rayanna dos Santos. A importância do psicólogo no processo de direito de família: Um estudo sobre a alienação parental. Revista Encantar-Educação, Cultura e Sociedade, v. 2, p. 01-13, 2020. Disponível em: http://www.revistas.uneb.br/index.php/encantar/ article/view/6080. Acesso em: 05 jun.. 2020.

SCHERBAUM, Júlia Francieli Neves; ROCHA, Leonel Severo. A constitucionalização no direito de família no sistema jurídico brasileiro. Revista de Constitucionalização do Direito Brasileiro [RECONTO], v. 1, n. 1, p. 1-21, 2018. Disponível em: http://revistareconto.com.br/index.php/Reconto/article/view/62. Acesso em: 13 maio. 2020.

SCHREIBER, Anderson. Direito Civil e Constituição. In: SCHREIBER, Anderson; KONDER, Carlos Nelson (coord.). Direito civil constitucional. São Paulo: Atlas, 2016, p. 1-23.

SILVA, Priscilla Nascimento; CARACIOLA, Andrea Boari. Jurisdição contemporânea, meios alternativos de solução de conflitos e propriedade intelectual. Meritum, Revista de Direito da Universidade FUMEC, v. 13, n. 2, p. 445457, jul./dez., 2018. Disponível em: http://www.fumec.br/revistas/meritum/article/view/6431. Acesso em: 16 jun. 2020.

SPENGLER, Fabiana Marion. Uma nova abordagem dos conflitos sociojurídicos por meio do Direito Fraterno. Revista Direito em Debate, v. 15, n. 26, jul./dez., p. 33-56, 2006. Disponível em: https://200.17.87.11/index.php/ revistadireitoemdebate/article/view/676. Acesso em: 02 jun. 2020. 
STRANGER, Guilherme Gonçalves. Guarda de filhos. São Paulo: Editora Revista dos Tribunais, 1991.

TARTUCE, Fernanda. Processo civil no direito de família: teoria e prática. 4. ed. Rio de Janeiro: Forense; São Paulo: Método, 2019.

TARTUCE, Flávio. Direito civil, v. 1: Lei de Introdução e Parte Geral. 13. ed. rev., atual. e ampl. Rio de Janeiro: Forense, 2017.

TEIXEIRA, Ana Carolina Brochado; TEPEDINO, Gustavo (org.). Fundamentos do Direito Civil - vol. 6: Direito de família. Rio de Janeiro: Forense, 2020.

TOMASZEWSKI, Adauto de Almeida. Separação, violência e danos morais. São Paulo: Paulistanajur, 2004.

Recebido/Received: 21.06.2020.

Aprovado/Approved: 26.09.2020. 